\title{
A Study of the Inductive Power Transmission for Electric Vehicle
}

\author{
M.A.da Silva, G.P.Viajante, E.N.Chaves, G. Moraes, M.A.A.Freitas, S.B. Silva, O.C.Souto,V.R. \\ Bernadelli and M.E,Oliveira
}

\author{
Federal Institute of Education, Science and Technology of Goiás \\ Campus of Itumbiara - Goiás, (Brazil) \\ Phone/Fax number: 5564 343152005, e-mail: ghunterp@gmail.com
}

\begin{abstract}
The present article aims to study the existing technologies for inductive power transmission (IPT) and its main applications in the commercial field. Aiming to understand this technology and its main parameters, so that it is possible to build a critical knowledge about the operation and the main factors that influence in favor and against the high performance of the system. Through the theories and simulations throughout the study a prototype was constructed to validate the main concepts that encompass IPT. The final objective of the project is to collect the results obtained from the contextualization of the theme and to verify the feasibility of applying electric vehicle (VE) supply. A study was also carried out on the autonomy of an existing VE in the market and the advances of the technologies for its wireless charging. The experimental results are shown and discussed.
\end{abstract}

\section{Key words}

Inductive power transmission, Magnetic induction, Electric vehicle.

\section{Introduction}

The pioneering researcher on wireless power transmission was the physicist Nikola Tesla, a great inventor in mechanical engineering and electrotechnology fields. Tesla recorded numerous patents and his theoretical work form the basis of modern AC power systems, including polyphase systems for power distribution and AC motor, in which it had great impact at the start of the second industrial revolution.

In 1899 came the great dream of Tesla, which was a possibility of broad-scale transmission of electrical energy without a source of physical connection. Tesla had already demonstrated wireless transmission at short distances in his laboratory and from specialized trials. Tesla imagined a construction of special stations, towers, which would send electricity without physic communications across the globe [1].
The unfinished Wardenclyffe project was started, according to the patent [2] as towers about 57 meters high and would depend on standard generators fueled by gas, coal, oil or diesel as a source of energy. Soil and air would be the medium of transmission. Among theoretical bases failures such as assuming that as waves of traveling across the Earth without loss, high cost of the project and lack of investors made the project a failure.

Although the idea was not successful, it was from it that other scientists invested in research in the area. Tesla's pioneering technology has evolved and is already being used to charge mobile phones and much more complex projects. [3]

The simplest and most cost-effective method with the largest field of research and applicability currently is Inductive Power Transmission (IPT). It is a typical phenomenon that occurs in conventional transformers in which the transfer of energy from the primary circuit to the secondary circuit operates according to Maxwell's Equation (Ampere-Maxwell's circuit law) and the magnetic coupling law through Faraday's law of induction. Its principle of operation is simple, the transformers need an alternating current (AC), that when circulating in the primary circuit originates a variable magnetic field, whose flow when circulating in a ferromagnetic nucleus, will induce an electromotive force in the secondary circuit, consequently generating a secondary. [4][5].

The magnetic core of the transformers mechanically connect the primary and secondary circuit. This favors the magnetic coupling $(\mathrm{K})$ approaching a unit, when this magnetic core is withdrawn, that is when it is divided into two parts, a primary circuit and a secondary one, the coupling coefficient is reduced so it is necessary that the circuit primary current is excited by currents and frequencies that compensate for the low coupling, unlike conventional transformers that work with high efficiency at low frequencies, because as the frequency increases, also the losses by hysteresis and the losses by the induction of Foucault currents.[4]. 
The flowchart of figure 1 represents the main type of wireless transmission for short, medium and long distance.

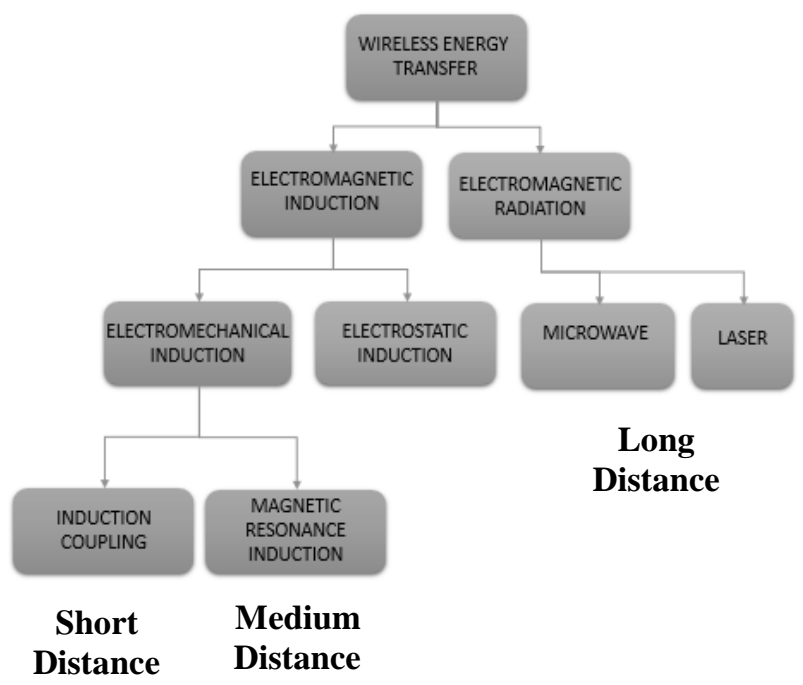

Fig. 1. Flowchart of existing methods of wireless electric energy transfer.

\section{Application of wireless energy in Electric Vehicles}

Its application is in the charging of traction batteries for electric vehicles, whether they are stopped or in motion, whereas, in the second case, the transfer of power occurs during the movement of the vehicle on an inductive charger. [3] Figures 2 and 3 illustrate vehicle loading at rest and in motion.

The main motivations that lead many researchers to invest time and money in this technology refer to the autonomy and convenience that this system can generate.

The first of these is the constant need to put it in a socket as well as electronic devices, but with a succinct restriction, which are the specific plug's that most of the vehicles have or standard charging bases. The second is the autonomy, the view of companies is to make possible the loading during their locomotion or stop, either in public parking lots, in their garage or even on highways.[3]

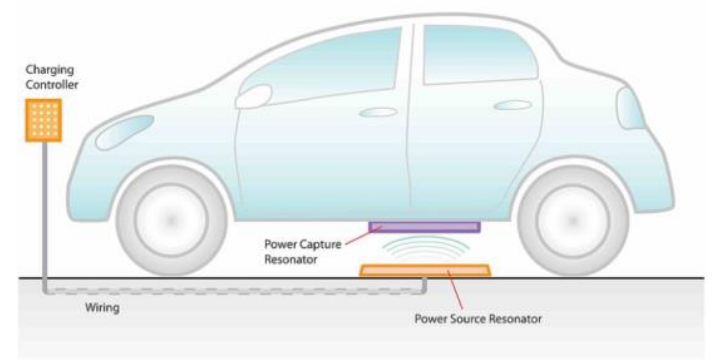

Fig. 2. Application in electric vehicles in resting vehicles [7]

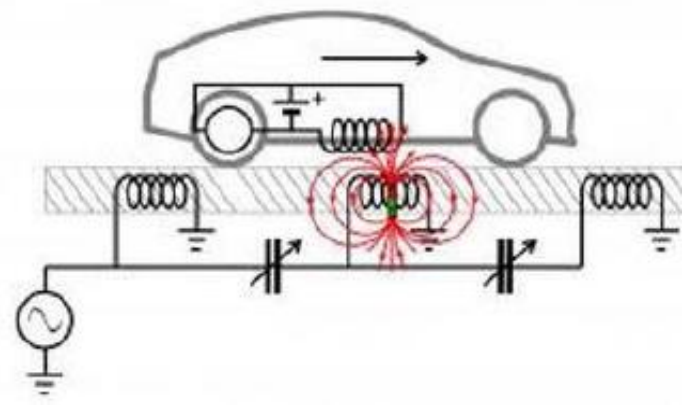

Fig. 3. Application in electric vehicles: in moving vehicles [7]

\section{Main parameters for studying the behavior of a wireless power system}

Unlike the system proposed by Nikolas Tesla in which he sought a solution for wireless transmission at long distances through high-intensity electric fields, the study carried out here is based on the magnetic coupling, where it is possible to obtain a transmission at short distances, which is ideal for residential applications, biomedical systems and charge electric vehicles [6].

These systems are based on RLC circuits in series or in parallel, consisting of an emitter circuit and a receiver that need to work at the same resonant frequency. [6] The resonance frequency is given by:

$$
f r=\frac{1}{2 \pi \sqrt{L C}}
$$

The coupling factor $(\mathrm{K})$ is another important parameter for designing an IPT system. The value of the coupling factor varies between 0 and 1 . The value 1 expresses a perfect coupling, that is, all the generated flow penetrates the receiving coil. The value 0 expresses that the coils of the transmitter and receiver circuit are independent. The coupling factor is given by mutual inductance between the coils $\left(\mathrm{M}_{12}\right)$ e self induction $\left(\mathrm{L}_{11}\right.$, $\mathrm{L}_{22}$ ) [6]:

$$
k=\frac{M_{12}}{\sqrt{L_{11} \cdot L_{22}}}
$$

In order to be able to determine the behavior of the system it is necessary to know the value of the Quality Factor, which is the stored energy lost per cycle. Therefore, a high $\mathrm{Q}$ value indicates low power loss and higher throughout of the system [6]. The Quality Factor is given by:

$$
\mathrm{Q}=\frac{f r L}{R s}
$$


where: $R s$ - Internal resistance of the inductor

From the value of the quality factor it is possible to obtain the value of the critical coefficient, through the equation (4).

$$
\text { Kcrític }=\frac{1}{Q}
$$

Through the obtained values of the critical coefficient it is possible to determine the behavior of the system comparing with the coefficient of coupling [9].

Through the values obtained from the critical coefficient it is possible to determine the type of coupling related to the values of the coupling factor $(\mathrm{K})$. Therefore the system can be critical when Kcritic $=K$, Subcritical when $O>K>$ Kcritic and Supercritical Kcritic $>K>1$. [6][9]

By analyzing the behavior of the system it is possible to observe factors to obtain the maximum power transmission.

\section{Experimental Platform}

In figure 4 , it is shown only the representation of the emitter circuit. It is possible to determine a value in the DC source where $R_{f}$ would be responsible for controlling the current supplied by the source. The value of the resistance $\mathrm{R}_{\mathrm{f}}$ does not influence the efficiency of the system, only in the final value of the induced voltages and currents in the emitting circuit [9].

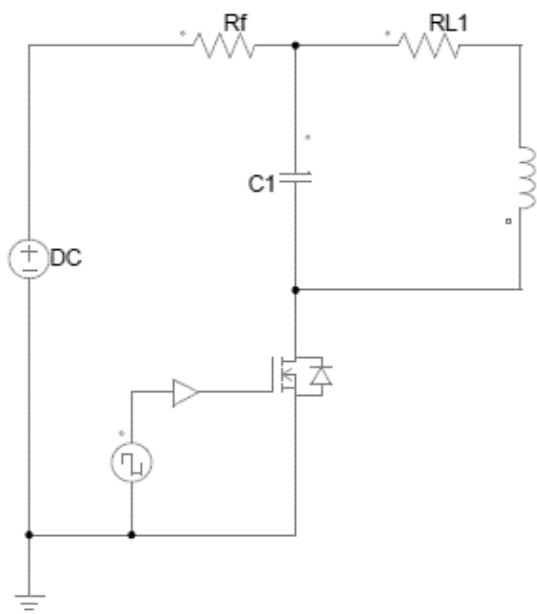

Fig. 4. RLC transmitter circuit

The receiver circuit operates in the same frequency range of the emitter circuit, so it is necessary to rectify it through the fast-trip diode for commercial use. In the figure 5 it is exhibited the representation of the receiver circuit. [9]

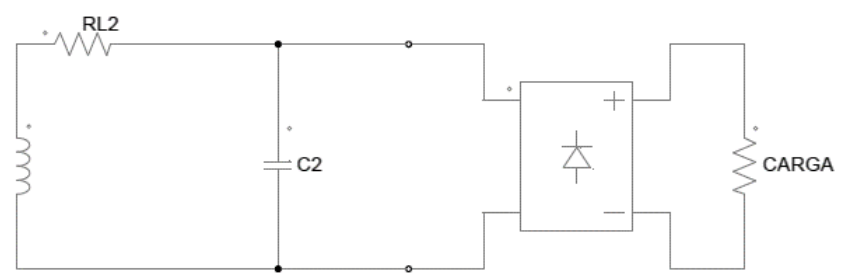

Fig. 5. RLC receiver circuit
In the construction of the physical prototype, the reel and emitter coil was constructed in a cylindrical spiral format. In the figure 6 it is shown the representation of the physical experiment and the tables I and II with the measured values of the mutual inductance by the distance and values of the components used in the construction of the circuit.

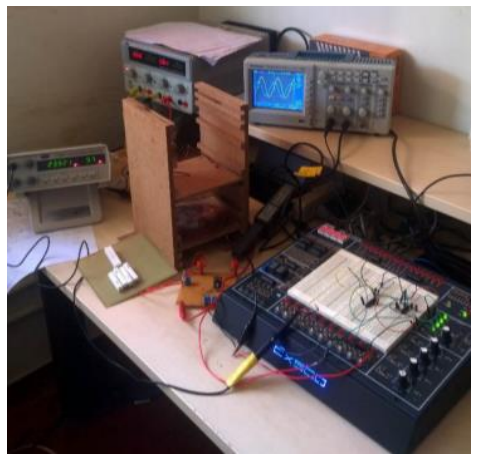

Fig. 6. Prototype of the project

Table I. - Mutual inductance variation with distance

\begin{tabular}{|c|c|c|}
\hline Distance & $\begin{array}{c}\text { Mutual } \\
\text { Inductance }\end{array}$ & Coupling Coefficien \\
\hline $1 \mathrm{~cm}$ & $6.2 \mathrm{uH}$ & 0.308461529 \\
\hline $5 \mathrm{~cm}$ & $5.4 \mathrm{uH}$ & 0.268660041 \\
\hline $10 \mathrm{~cm}$ & $1.1 \mathrm{uH}$ & 0.054727045 \\
\hline $15 \mathrm{~cm}$ & $0.88 \mathrm{uH}$ & 0.043781636 \\
\hline
\end{tabular}

Table II. - values of the components in the emitter and receiver circuit

\begin{tabular}{|c|c|}
\hline Components & Value \\
\hline Fonte $(\mathrm{DC})$ & $40 \mathrm{~V}$ \\
\hline $\mathrm{R}_{\mathrm{f}}$ & $10 \mathrm{Ohm}$ \\
\hline $\mathrm{R}_{\mathrm{L} 1} / \mathrm{R}_{\mathrm{L} 2}$ & $12.13 \mathrm{mOhm}$ \\
\hline $\mathrm{C}_{1} / \mathrm{C}_{2}$ & $2.2 \mathrm{uF}$ \\
\hline $\mathrm{L}_{1} / \mathrm{L}_{2}$ & $20.2 \mathrm{uH}$ \\
\hline Rcarga & $100 \mathrm{kOhm}$ \\
\hline
\end{tabular}

\section{Experimental Results}

First measurements were made using the uncharged receiver circuit for distances of 5,10 and $15 \mathrm{~cm}$. The results obtained are shown in Figures 7, 8 and 9. Channel 1 corresponds to the emitter circuit and channel 2 to the receiver circuit. The source voltage was $23 \mathrm{~V}$.

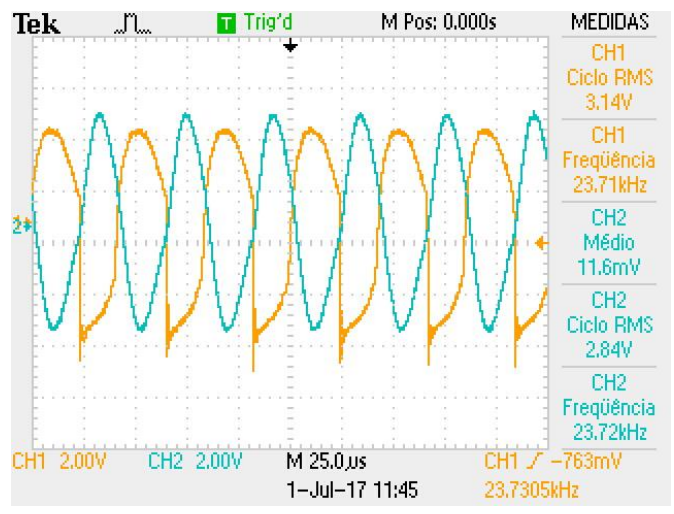

Fig. 7. Transmitter voltage and receiver at $5 \mathrm{~cm}$ distance 


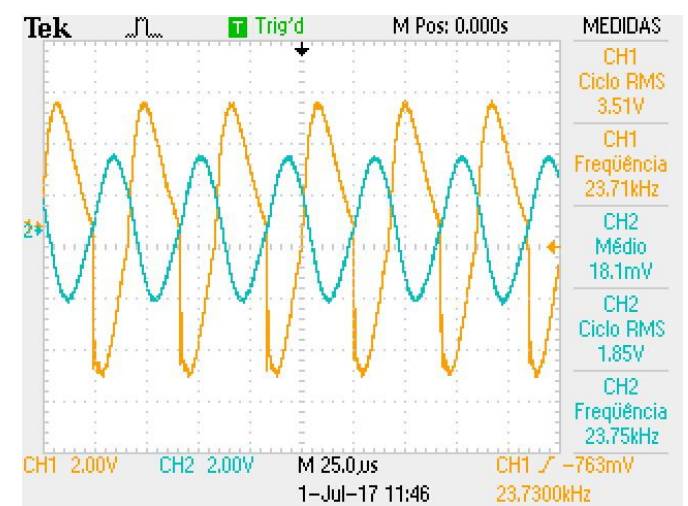

Fig. 8. Transmitter voltage and receiver at $10 \mathrm{~cm}$ distance

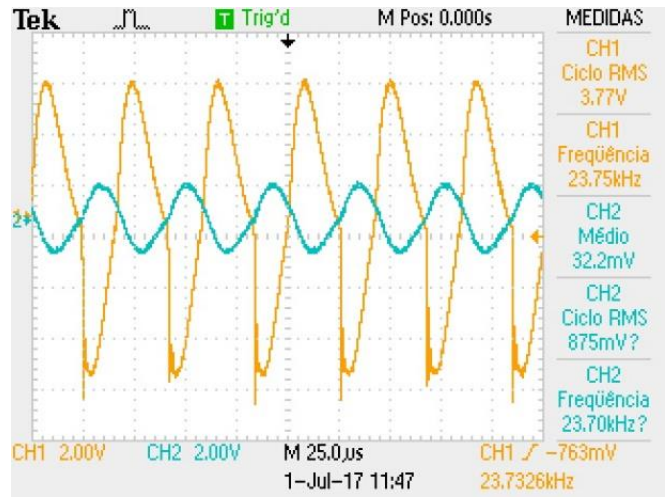

Fig. 9. Transmitter voltage and receiver at $15 \mathrm{~cm}$ distance

Table III summarizes these results:

Table III. - Induced voltage variation in relation to distance and transfer efficiency

\begin{tabular}{|c|c|c|c|}
\hline $\begin{array}{c}\text { Distance } \\
(\mathrm{cm})\end{array}$ & $\begin{array}{c}\text { Voltage } \\
\text { Transmitter } \\
(\mathrm{V})\end{array}$ & $\begin{array}{c}\text { Voltage } \\
\text { Receiver }(\mathrm{V})\end{array}$ & efficiency (\%) \\
\hline $5 \mathrm{~cm}$ & 3.14 & 2.84 & 90.45 \\
\hline $10 \mathrm{~cm}$ & 3.51 & 1.85 & 52.71 \\
\hline $15 \mathrm{~cm}$ & 3.77 & 0.875 & 23.21 \\
\hline
\end{tabular}

It is important to return to analysing coupling coefficient to understand how the value of the comments participated influence the efficiency of the system.

With the amounts collected it was possible to plot the graphic of Figure 10 wich shows the influence of the distance on the value of the mutual inductance.

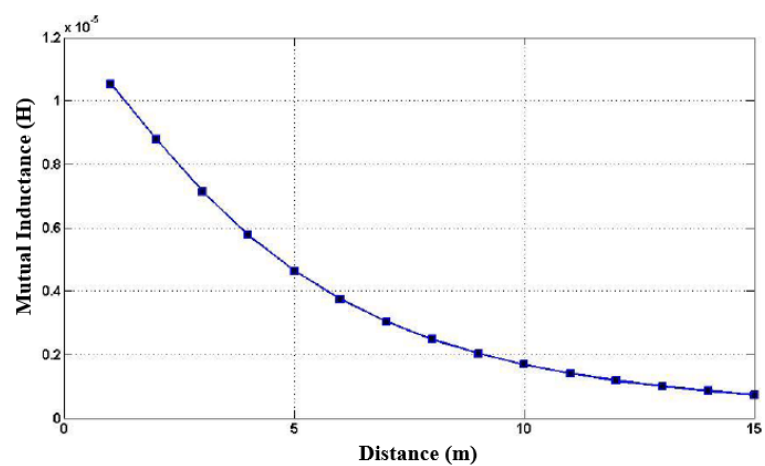

Fig. 10. Theoretical relationship between mutual inductance and distance

By the ratio of proportionality of the critical coefficient to the mutual inductance of equation 2, it is obtained the following curve:

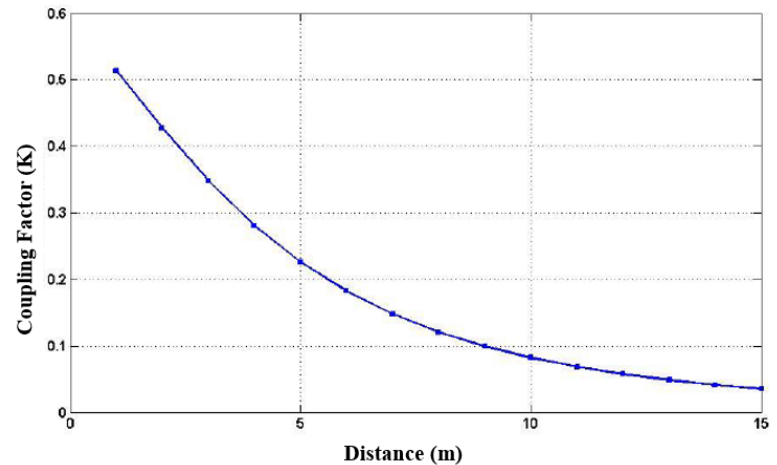

Fig. 11. Theoretical relationship between coupling factor and distance

Therefore, the smaller the mutual inductance the smaller the coupling coefficient. It is known that the closer to zero the coupling coefficient is more decoupled. These results is exhibited in the figure 12 .

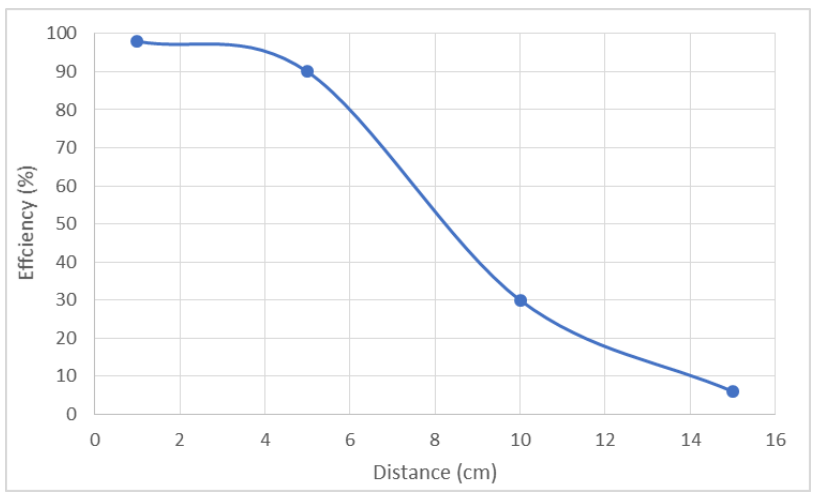

Fig. 12. Variation of transmission efficiency with respect to distance

Besides the system working with high coupling factor, in order to have high efficiency it is necessary that the system is resonant, working at the same frequency. From the figure 13 it can be observed that the maximum power transfer occurs at the resonance frequency of the RLC circuit.

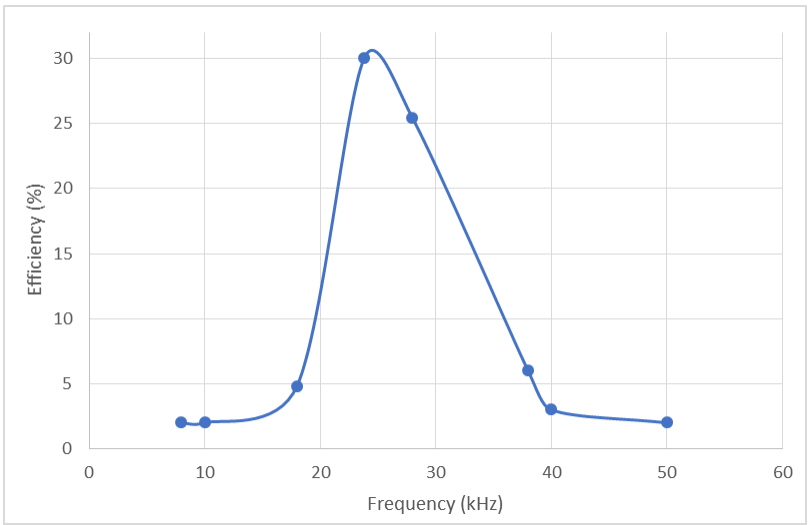

Fig. 13. - Variation of transmission efficiency in relation to frequency 
Therefore the main points that influence the efficiency of a wireless energy transmission system are frequency, load and distance.

Although the results of this technology show significant losses with the distance, there are other technologies in development that promise a satisfactory efficiency. A team of researchers at ITMO University in Russia, proposed a new Wireless Power system. According to numerical simulations, the proposed system can maintain a transfer efficiency of $80 \%$ over a distance of $20 \mathrm{~cm}$, while suffering only a very small decrease in efficiency as the distance increases. The paper was recently published in 2016 in a recent issue of Applied Physics Letters [7].

Figure 13 illustrates the comparison between the systems proposed to date, with the blue line being the proposed MIT system, red the magnetic dipole system and the green the new quadrupole system using ceramic resonators.

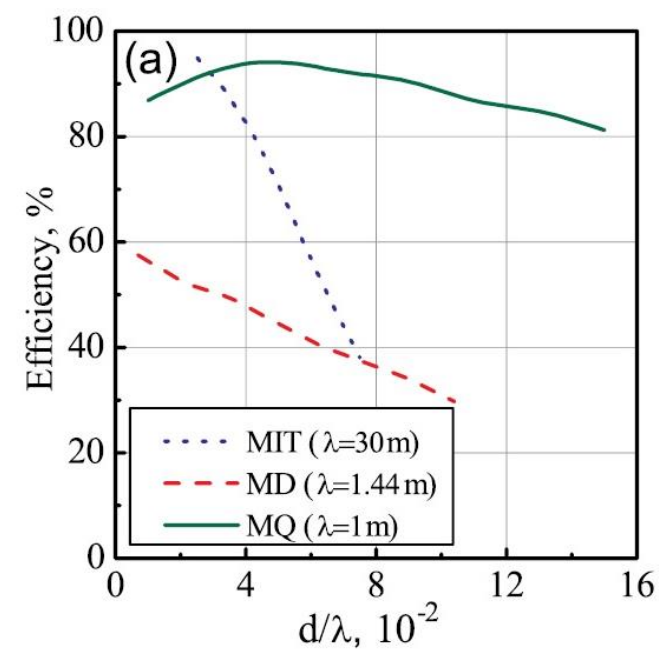

Fig. 13. - Comparison between proposed Witricity systems [7]

\section{Conclusion}

This paper presented a study on wireless power transfer. It was shown the main parameters that influence the behavior of energy transmission, such as: resonance frequency, coupling factor and quality factor. It was also shown the relationship between coupling factor and distance, the variation of transmission efficiency with respect to distance, the relationship between mutual inductance and distance and finally, the variation of transmission efficiency in relation to frequency. The great barrier to this leverage technology is the low efficiency that the system draws from the distance. In the case of the charging of the electric car that distance is necessary and to maintaining a high efficiency it is necessary to keep the coupling factor high, something that in the ITP system is not easy to do. As research in this area is progressing very fast, it is possible that researchers will be able to use new transfer methods to use other types of systems, but ITP still remains the cheapest and most widely used system in the market today.

\section{Acknowledgement}

The authors would like to thank IFG for the financial support.

\section{References}

[1] William C. Brown, "The history of power transmission by radio waves", Microwave Theory and Techniques, IEEE Transactions, 32(9):1230-1242, September 1984.

[2] Apparatus for transmitting electrical energy. V N. TBSLA. Abparatus for transmitting electrical energy. Application filed janjb, 1902. RENEWED MAY 4, 1907. Patented Dec. 1,1914. Avaliable: https://www.google.com/patents/US1119732?hl=ptBR, Access: 02/01/17.

[3] M. FELIPE, "Transmissão indutiva de energia eletromagnética sem fios, para aplicações em postos de abastecimento de veículos elétricos puros: modelação para o elemento eletromagnético". UNESP, Ilha Solteira 2015, pp 1720.

[4] A.B. Kurs, A. Karalis, R. Moffatt, J.D. Joannopoulos, P.H. Fisher, and M. Soljacic, "Wireless Power Transfer via Strongly Coupled Magnetic Resonances", Science, 317, pp. 8386,(2007).

[5] A. Karalis, J.D. Joannopoulos, and M. Soljacic, "Efficient Wireless Non-radiative Midrange Energy Transfer", Ann. Phys., 323, pp. 34-48, (2008); published online April 2007.

[6] W. GRABRIEL, "Analise experimental da transmissao de energia sem fio por modos ressonantes. Dissertação ( Mestrado)". Universidade Federal de Uberlândia, 2016, pp. 3160

[7] M. SONG, M. IORSH, I. KAPITANOVA, P. NENASHEVA, E. BELOV , Pavel,"Wireless power transfer based on magnetic quadrupole coupling in dielectric resonators". Applied Physics Letters, 2016, pp. 1-3

[8] R. ALEXANDRA, "Transmissão de Energia sem contato com aplicação em veículos elétricos. Universidade Nova de Lisboa", Setembro de 2011.

[9] W1.GRABRIEL, "Analise experimental da transmissao de energia sem fio por modos resonantes".Dissertação (Mestrado). Universidade Federal de Uberlândia, 2016. 